\title{
GÓMEZ GARCÍA, LUZ (2009): DICCIONARIO DE ISLAM E ISLAMISMO. MADRID, ESPASA CALPE, 412 PÁGS.
}

\author{
Ruth María Lavale Ortiz \\ Universidad de Alicante \\ ruth.lavale@ua.es
}

El Diccionario de islam e islamismo surge como consecuencia del creciente interés en los últimos años en España por la cultura islámica y por la política del islamismo, así como por la confusión que suscita la aparición de términos árabes en los periódicos sin la existencia de una obra que ordene y explique estos conceptos. Este vacío bibliográfico ha aventurado a Luz Gómez a escribir este diccionario, con la finalidad de proporcionar una obra exacta y precisa en la que se expliquen los conceptos, se los dote de una ortografía que llegue a ser unánime y se eviten los malentendidos que ha provocado el uso poco riguroso de la terminología árabe. La selección de las 500 palabras que aparecen en el diccionario se ha realizado observando minuciosamente los términos árabes que son utilizados con mayor frecuencia en la prensa española, por lo que se trata de un vocabulario de uso cotidiano y actual. Este conjunto de términos conforma un diccionario temático, que no lexicográfico, en el que se conjugan diferentes disciplinas, dando lugar a una obra completa accesible al gran público.

La obra se encuentra estructurada en seis partes. Las dos primeras partes tienen un carácter introductorio y se dedican al preámbulo de la obra y a explicar cómo debe utilizarse el diccionario. En la tercera parte se recogen las entradas del diccionario, por lo que constituye el grueso de la obra. Finalmente, el diccionario se cierra con una cronología, una bibliografía general por temas y cuatro índices.

El preámbulo del diccionario es una declaración de intenciones sobre la obra. La autora comenta, en este apartado inicial, cómo ha concebido el diccionario, por qué y para qué. En este diccionario, Luz Gómez ha pretendido mostrar cómo el Islam, término referido a la doctrina y a la religión, se ha visto influido y transformado por el islamismo, palabra que designa una ideología o política; entre estos dos polos ha habido una gran tensión que ha provocado cambios en el seno del Islam a través de diferentes contextos sociales, políticos, geográficos, culturales y temporales. Concretamente, las entradas pretenden dar una visión del Islam contemporáneo, por lo que la autora deja de lado hechos relacionados con la historia del Islam clásico. Puesto que su interés es mostrar el empleo de estas voces en el español contemporáneo, acredita su utilización a través de citas tomadas de la prensa nacional española. Luz Gómez propone con su obra una unificación ortográfica de los conceptos árabes; tal y como señala, en la prensa española se recogen con mucha frecuencia vocablos árabes, pero existe una gran vacilación a la hora de escribir un mismo término. Esta situación provoca desconcierto en el lector, lo que puede desembocar en un alejamiento y un rechazo hacia el Islam. El diccionario, en suma, introduce una innovación en nuestra bibliografía, porque en nuestra 
lengua hay estudios relacionados con el Islam y el islamismo, pero no se proporciona una visión tan interdisciplinar como la autora adopta en su diccionario, lo que, sin duda alguna, enriquece la obra.

A continuación, y de forma previa al diccionario, la autora dedica un apartado a explicar cómo debe utilizarse la obra. En él nos proporciona instrucciones muy precisas sobre cómo se han transliterado las palabras y cómo se ha llevado a cabo la adaptación del vocabulario árabe, persa y urdu. Asimismo, explica la organización alfabética de las entradas del diccionario e indica las abreviaturas y signos tipográficos que ha utilizado. En este punto también señala que los lemas están siempre ejemplificados en su parte final; se trata de citas, obtenidas siempre del ámbito periodístico, que en algunas ocasiones sirven únicamente para demostrar que el término se utiliza en la prensa española y, en otras, ejemplifican semánticamente su uso.

Seguidamente, da comienzo el grueso de la obra: el diccionario, ordenado alfabéticamente. Los términos que explica la autora son, en su mayoría, nombres comunes, que hacen referencia a las instituciones, dogmas, creencias, ritos, prácticas y normas del Islam actual; únicamente se recogen los nombres propios Corán, Mahoma, Ali, Abraham, Arabia, La Meca, Medina y Al-Ándalus, básicos para la comprensión del mundo islámico. La estructura de los artículos es muy sencilla: en primer lugar encontramos el lema, que, si no está recogido en el Diccionario de la lengua española de la Real Academia Española, irá acompañado de la indicación de la lengua de la que proviene (a excepción del árabe), así como de la forma original cuando el término pertenezca a las lenguas árabe, persa o urdu; a continuación, descubrimos la definición o explicación semántica del término; posteriormente, encontramos información lingüística, política, religiosa, histórica, social, geográfica, etc.; finalmente, aparece la cita que ejemplifica el uso del vocablo en los periódicos actuales. En el diccionario, la extensión de los artículos es muy variable: descubrimos explicaciones de apenas una línea (como es el caso de ahl o jerifato), y términos que precisan de varias páginas de explicación (como sucede con tafsir o islamismo); tal y como señala la autora en el preámbulo, la extensión de los artículos varía según la complejidad conceptual del término o de los diferentes matices contextuales que presenta y no de su protagonismo en el mundo islámico. En el desarrollo de los artículos también es posible encontrar cuadros explicativos (como los que indican los meses del calendario islámico o los estados miembros de la Organización de la Conferencia Islámica de 2008), esquemas (como el dedicado a las ramificaciones de chía) y gráfícos (como el de las principales corrientes ideológicas sunníes del siglo XX). La información más relevante incluida en las explicaciones la constituyen los datos contemporáneos que introduce la autora, ya que, siguiendo con el objetivo que pretende Luz Gómez, sirven para comprender el Islam y el islamismo desde el punto de vista español y contemporáneo. Finalmente, hay que destacar las citas o ejemplos que introduce la autora al final de los artículos. Estas citas se han extraído de los periódicos Abc, El Mundo, El País, La Razón y La Vanguardia. Son ejemplos actuales (el más antiguo es de 1982) que atestiguan la utilización de los vocablos en la prensa española y permiten entender mejor los términos y mostrar objetivamente su uso. En algunos casos, la transliteración de las palabras que propone la autora en el diccionario no coincide con las grafías utilizadas por los periodistas; esto se debe a la confusión reinante hasta el momento a la hora de utilizar los términos árabes, ya que no existía una obra que tratara de unificar con rigor científico su escritura; este desencuentro provoca breves comentarios de la autora en los que demuestra su deseo de homogeneización a la hora de adaptar las 
palabras de procedencia árabe, puesto que las variaciones a la hora de escribir los términos pueden provocar, $\mathrm{y}$, de hecho, provocan, variaciones en la interpretación por parte el lector.

La cronología es un breve pero exhaustivo apartado de ocho páginas en el que se recogen los datos históricos esenciales del Islam y el islamismo desde el año 610 hasta el 2008. Este punto es de gran utilidad para todo tipo de lectores, puesto que se trata de datos muy precisos que ayudan a conocer mejor los acontecimientos que han provocado la aparición de ciertos términos o que han producido la evolución de significado de muchos otros.

El apartado de bibliografía resulta significativo y útil para los interesados en el mundo islámico. Se trata de una bibliografía por temas, en la que la autora detalla obras que nos ayudan a introducirnos al Islam (obras generales, diccionarios y obras de consulta), referencias que sirven para entender cuestiones relacionadas con el Corán, Hadiz y Mahoma; la teología, la filosofía y el derecho; la historia del Islam; su diversidad cultural y social; la situación contemporánea del Islam y el islamismo; el Islam y los estudios de área y, finalmente, las cuestiones relacionadas con el arte, las letras y la ciencia. Es, por lo tanto, un estudiado y minucioso catálogo de referencias bibliográficas que abarca obras clásicas y actuales, proporcionando así, al estudioso en la materia, una fuente de información muy valiosa.

En último lugar encontramos cuatro índices. El primero, de términos, en el que se recogen los lemas del diccionario, algunos términos de carácter temático que facilitan la consulta, los términos que aparecen en el cuerpo del diccionario y las formas con las que se representan en la prensa escrita; asimismo, la autora señala en este índice de términos cuáles son las palabras que se encuentran recogidas en el Diccionario de la Lengua Española de la Real Academia Española e indica los casos en que las acepciones académicas difieren de las que ella introduce. El segundo índice recoge los nombres de personas, dinastías, pueblos y tribus mencionados en el diccionario. En el tercer índice encontramos los nombres de lugar y, en el último, los acontecimientos, organizaciones, empresas e instituciones que se citan en el diccionario. Los índices resultan de gran interés para cualquier investigador del Islam y el islamismo que desee acudir directamente a los aspectos relacionados con su tema de estudio, así como para aquellos lectores interesados en ampliar su conocimiento sobre cuestiones determinadas.

El Diccionario de islam e islamismo viene a llenar el vacío existente en España de obras que entienden y explican el Islam y su terminología desde una perspectiva española. En la actualidad, el mundo islámico posee una gran repercusión en nuestro país y muestra de ello es la gran cantidad de términos que podemos leer cada día en los periódicos. Sin embargo, el caos reina a la hora de transcribir e interpretar los diferentes vocablos, lo que provoca una gran confusión en el lector, y el diccionario de Luz Gómez surge como obra de referencia que unifica criterios, que proporciona rigor e información de tipo interdisciplinar. De esta forma, se constituye en una referencia obligada para los periodistas que deseen escribir sobre el Islam y el islamismo, para los políticos, cooperantes, sociólogos e historiadores que trabajen y estudien con temas islámicos y para los docentes que enseñen el mundo islámico en su totalidad. Asimismo, este diccionario es una obra accesible al público no versado en temas islámicos, pues su lectura resulta sencilla y sumamente enriquecedora, ya que se trata de un diccionario por temas, que aporta información muy variada (lingüística, política, histórica, ideológica, religiosa, social, etc.). 